Bangladesh J. Sci. Ind. Res. 42(4), 449-454, 2007

\title{
Metroglyph Analysis in Cotton (Gossypium Sp.)
}

\author{
M.R. Khan, A. Samad, S. Begum, S. Khaleda, A.K.M.S. Alam, \\ A.N. Chowdhury and M.Z. Rahman \\ BCSIR Laboratories, Rajshahi, Bangladesh
}

\begin{abstract}
Pattern of morphological variations was studied in seven cultivars of cotton viz. (1) DPL-41, (2) DPL-20, (3) BAC-49, (4) DPL-50, (5) DPL-51, (6) JA/96-B and (7) DPL-90 by metroglyph and index score method (Anderson, 1957). Two most variable characters - plant height at maturity (PHM) and fibre yield per plant (FYP) were selected for $\mathrm{X}$ and $\mathrm{Y}$ axis, respectively. In metroglyph diagram there appeared two clusters one comprised of 2 and the other comprised of 3 cultivars. Cluster I representing cultivar nos. 1 and 2 and cluster II cultivar nos. 4, 5 and 7. In both the clusters (Cluster I and II) the members are not so closely associated. In cluster I the members seems to form a straight line and in cluster II they form a triangle. An exceptional feature is the off location of two glyphs representing cultivar nos. 3 and 6.
\end{abstract}

\section{Key words:}

\section{Introduction}

The genus Gossypium belongs to the family Malvaceae is divided into three species on the basis of fibre quality. These are (i) $G$. barbadense with a fibre length of $37 \mathrm{~mm}$ which is cultivated in Egypt and Sudan. This is also known as Egyptian, American Egyptian and C-Island varieties, (ii) G. hirsuta with a fibre length ranging from 25-30 $\mathrm{mm}$. Ninety percent of world's cultivated cotton is under this species. The above two species are also known as New World Cotton and (iii) G. arboreum and G. harbaceum are also known as Asiatic or Old World Cotton. The fibre length is less than $25 \mathrm{~mm}$ in length.
G.arboreum is also known as Comilla Cotton. It is cultivated in Rangamati, Khagrachari, Banderban districts and Garo hill regions of Mymensingh district of Bangladesh. It is also cultivated commercially in Myanmar, Thailand, Indonesia, Vietnam, The Phillipines and Nepal. On the other hand G. harbeceum is cultivated in India and Pakistan. The fibres of these species are thick and rough in nature.

Available germplasm of cotton can be catalogued systematically on the basis of morphological data. Among the cultivated cotton varieties there exists a great deal of variation 
regarding morphological characters. To study the pattern of morphological variation in crop species Anderson (1957) proposed metroglyph and index score method. Several workers (Ramanujan and Kumar 1964, Mukherjee et al.1971, Kabir et al. 1993, Khan and Kabir, 1996) used this technique in various crops to study the pattern of morphological variations. In Bangladesh, this is for the first time; attempt has been made to predict genetic diversity in different cultivars of cotton now available and grown in our country.

\section{Materials and Methods}

The materials used in this study were seven varieties of cotton viz. (1) DPL-41, (2) DPL20, (3) BAC-49, (4) DPL-50, (5) DPL-51, (6) JA/96-B and (7) DPL-90. All these cultivars were collected from Cotton Research Center, Jessore and Dinajpur. The collected seven varieties were grown under uniform field conditions with three replications of each. Ten plants were randomly selected and observations were made on 10 morphological characters. The characters studied were days to first flowering (DFF), plant height at first flowering (PHFF), number of branches at first flowering (NBFF), number of leaves at first flowering (NLFF), plant spreading at first flowering (PSFF), plant height at maturity (PHM), number of balls at maturity (NBM), ball weight (BW), number of seed per ball (NSB) and fibre yield per plant (FYP).
In order to analyze the pattern of morphological variations metroglyph and index score method (Anderson, 1957) was used. Fibre yield per plant (FYP) and plant height at maturity (PHM) - the two most variable characters were selected for $\mathrm{X}$ and $\mathrm{Y}$ axis, respectively. A particular character was represented by a glyph, the $\mathrm{X}$ axis being the fibre yield per plant (FYP) and the $\mathrm{Y}$ axis being the plant height at maturity (PHM). Seven characters were represented by rays on the glyph, the ray for the same character having the same position in each glyph. The range of variation in each character was represented by varying length of rays, i.e., a cultivar having low value with no ray, medium value with short ray and high value with long ray. Thus the length of the ray was either nil, short or long depending on the index values which were decided on the basis of range variability. They were divided into three classes, i.e., 1- no ray, 2- short ray and 3long ray (Table II). The total index values were recorded by summing up the score of all the ten characters studied (Table I). The minimum and maximum scores that an individual could get was $n \times 1$ and $n \times 3$, respectively, where $\mathrm{n}$ was the total number of characters considered.

\section{Results and Discussion}

Table I, shows mean data and scores (in brackets) for different characters of seven cultivars of cotton. The highest score (19) was observed in cultivar JA/96-B and the 
Table I. Mean data and scores (in brackets) for different characters of seven cultivars of cotton

\begin{tabular}{l|c|c|c|c|c|c|c|c|c}
\hline $\begin{array}{l}\text { Characters } \\
\text { Cultivars }\end{array}$ & DFF & PHFF & NBFF & NLFF & PSFF & NBM & BW & NSB & $\begin{array}{c}\text { Total* } \\
\text { score }\end{array}$ \\
\hline 1. DPL-41 & 79.50 & 73.40 & 10.70 & 49.70 & 89.50 & 11.90 & 4.01 & 30.33 & 13 \\
& $(2)$ & $(1)$ & $(2)$ & $(1)$ & $(3)$ & $(1)$ & $(1)$ & $(2)$ & \\
2. DPL-20 & 80.80 & 71.80 & 9.80 & 48.90 & 74.60 & 12.10 & 3.48 & 36.33 & 12 \\
& $(3)$ & $(1)$ & $(1)$ & $(1)$ & $(1)$ & $(1)$ & $(1)$ & $(3)$ & \\
3. BAC-49 & 76.20 & 82.20 & 12.50 & 57.10 & 64.90 & 22.10 & 4.47 & 32.0 & 17 \\
& $(1)$ & $(3)$ & $(3)$ & $(2)$ & $(1)$ & $(2)$ & $(2)$ & $(3)$ & \\
4. DPL-50 & 80.30 & 71.60 & 11.00 & 50.00 & 82.50 & 16.00 & 5.48 & 34.67 & 16 \\
& $(2)$ & $(1)$ & $(2)$ & $(2)$ & $(2)$ & $(1)$ & $(3)$ & $(3)$ & \\
5. DPL-51 & 80.90 & 84.60 & 11.10 & 64.50 & 95.20 & 20.70 & 4.19 & 22.67 & 19 \\
& $(3)$ & $(3)$ & $(2)$ & $(3)$ & $(3)$ & $(2)$ & $(2)$ & $(1)$ & \\
6. JA/96-B & 83.00 & 84.00 & 12.20 & 62.90 & 92.50 & 35.20 & 5.28 & 30.33 & 23 \\
& $(3)$ & $(3)$ & $(3)$ & $(3)$ & $(3)$ & $(3)$ & $(3)$ & $(2)$ & \\
7. DPL-90 & 81.30 & 77.60 & 10.10 & 50.40 & 76.30 & 11.20 & 4.19 & 31.67 & 14 \\
& $(3)$ & $(2)$ & $(1)$ & $(1)$ & $(2)$ & $(1)$ & $(2)$ & $(2)$ & \\
\hline
\end{tabular}

*Sum of scores of all characters excluding FYP and PHM, those were for X axis and Y axis, respectively.

lowest was recorded (12) in DPL-20, The cultivar DPL-51 also showed high score followed by the cultivars Bac-49, DPL-50 and DPL-90. The sum of scores of the characters FYP and PHM were used for $\mathrm{X}$ axis and $\mathrm{Y}$ axis, respectively in the metroglyph diagram.

Table II, represents class intervals, index values and distribution of scores of seven cultivars of cotton under different character intensities. The index values were classified into three classes (1,2 and 3) by partitioning the range of means in each case.
Metroglyph analysis representing in Fig. 1 illustrate the pattern of morphological variations. Cultivars under study were found to segregate in different way with a tendency to increase in fibre yield per plant (FYP) and plant height at maturity (PHM) i.e., two most variable characters used for determining $\mathrm{X}$ and $\mathrm{Y}$ axis, respectively and thus for construction of metroglyph pattern.

In the metroglyph diagram (Fig. 1) there appeared two clusters one comprised of 2 and the other comprised of 3 cultivars. Cluster I representing cultivar nos. 1 and 2. 
Table II. Class intervals, index values and distribution of scores of seven cultivars of cotton under different character intensities

\begin{tabular}{|c|c|c|c|c|c|c|c|}
\hline \multirow[b]{2}{*}{ Characters } & \multirow[b]{2}{*}{$\begin{array}{l}\text { Range of } \\
\text { means }\end{array}$} & \multicolumn{6}{|c|}{ Index values } \\
\hline & & $\begin{array}{l}1 \\
\text { Values } \\
<\end{array}$ & Sign & $\begin{array}{l}2 \\
\text { Values } \\
\text { from to }\end{array}$ & Sign & $\begin{array}{l}3 \\
\text { Values } \\
< \\
\end{array}$ & Sign \\
\hline DFF & $76.20-83.00$ & $\begin{array}{l}78.46 \\
(1)\end{array}$ & & $\begin{array}{l}\text { 78.47-80.73 } \\
\text { (2) }\end{array}$ & & $\begin{array}{c}80.74 \\
(4)\end{array}$ & \\
\hline PHFF & $71.60-84.60$ & $\begin{array}{c}75.9 \\
(3)\end{array}$ & & $\begin{array}{c}75.94-80.26 \\
\text { (1) }\end{array}$ & & $\begin{array}{l}80.27 \\
(3)\end{array}$ & \\
\hline $\mathrm{NBFF}$ & $9.80-12.20$ & $\begin{array}{c}10.60 \\
(2)\end{array}$ & C & $\begin{array}{c}10.61-11.40 \\
\text { (3) }\end{array}$ & & $\begin{array}{c}11.41 \\
(2)\end{array}$ & \\
\hline NLFF & $48.90-64.50$ & $\begin{array}{l}54.10 \\
(3)\end{array}$ & 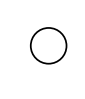 & $\begin{array}{c}54.11-59.30(2) \\
\text { (2) }\end{array}$ & & $\begin{array}{c}59.31 \\
(2)\end{array}$ & \\
\hline PSFF & $64.90-95.20$ & $\begin{array}{l}75.00 \\
(2)\end{array}$ & & $\begin{array}{l}\text { 75.01-85.10 } \\
\text { (2) }\end{array}$ & & $\begin{array}{c}85.11 \\
(1)\end{array}$ & \\
\hline PHM & $\begin{array}{c}101.60-155.00 \\
\text { (X axis) }\end{array}$ & $\begin{array}{l}119.40 \\
(3)\end{array}$ & 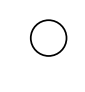 & $\begin{array}{c}119.41-137.20 \\
\text { (3) }\end{array}$ & & $\begin{array}{c}137.21 \\
(1)\end{array}$ & \\
\hline NBM & $11.20-35.20$ & $\begin{array}{l}19.20(4) \\
(4)\end{array}$ & 0 & $\begin{array}{l}19.21-27.20 \\
(2)\end{array}$ & & $\begin{array}{c}27.21 \\
(1)\end{array}$ & \\
\hline BW & $3.48-5.48$ & $\begin{array}{c}4.15 \\
(2)\end{array}$ & 7 & $\begin{array}{l}4.16-4.82 \\
\text { (3) }\end{array}$ & & $\begin{array}{l}4.83 \\
(2)\end{array}$ & \\
\hline NSB & 22.67-36.33 & $\begin{array}{l}27.22 \\
(3)\end{array}$ & 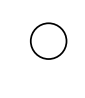 & $\begin{array}{c}27.23-31.77 \\
\text { (3) }\end{array}$ & & $\begin{array}{l}31.78 \\
(3)\end{array}$ & \\
\hline FYP & $\begin{array}{l}29.55-147.88 \\
\text { (Y axis) }\end{array}$ & $\begin{array}{c}68.99 \\
(3)\end{array}$ & $C$ & $\begin{array}{c}69.00-108.43(2) \\
(2)\end{array}$ & & $\begin{array}{l}108.44 \\
(2)\end{array}$ & \\
\hline
\end{tabular}

(Number of scores shown in brackets)

The cultivars in this cluster are not so closely associated. Cultivar no. 1 showed high value for plant spreading at first flowering (PSFF), cultivar no. 2 for days to first flowering (DFF) and number of seed per ball (NSB). For rest of the characters both the cultivars (nos. 1 and 2) showed medium and low values.
In cluster II the members are cultivar nos. 4, 5 and 7. These three cultivars were also scattered as in cluster I. In this cluster cultivar no. 4 revealed high value for ball weight (BW) and number of seeds per ball (NSB), cultivar no. 5 for days to first flowering (DFF), plant height at first flowering (PHFF), number of leaves at first flowering 


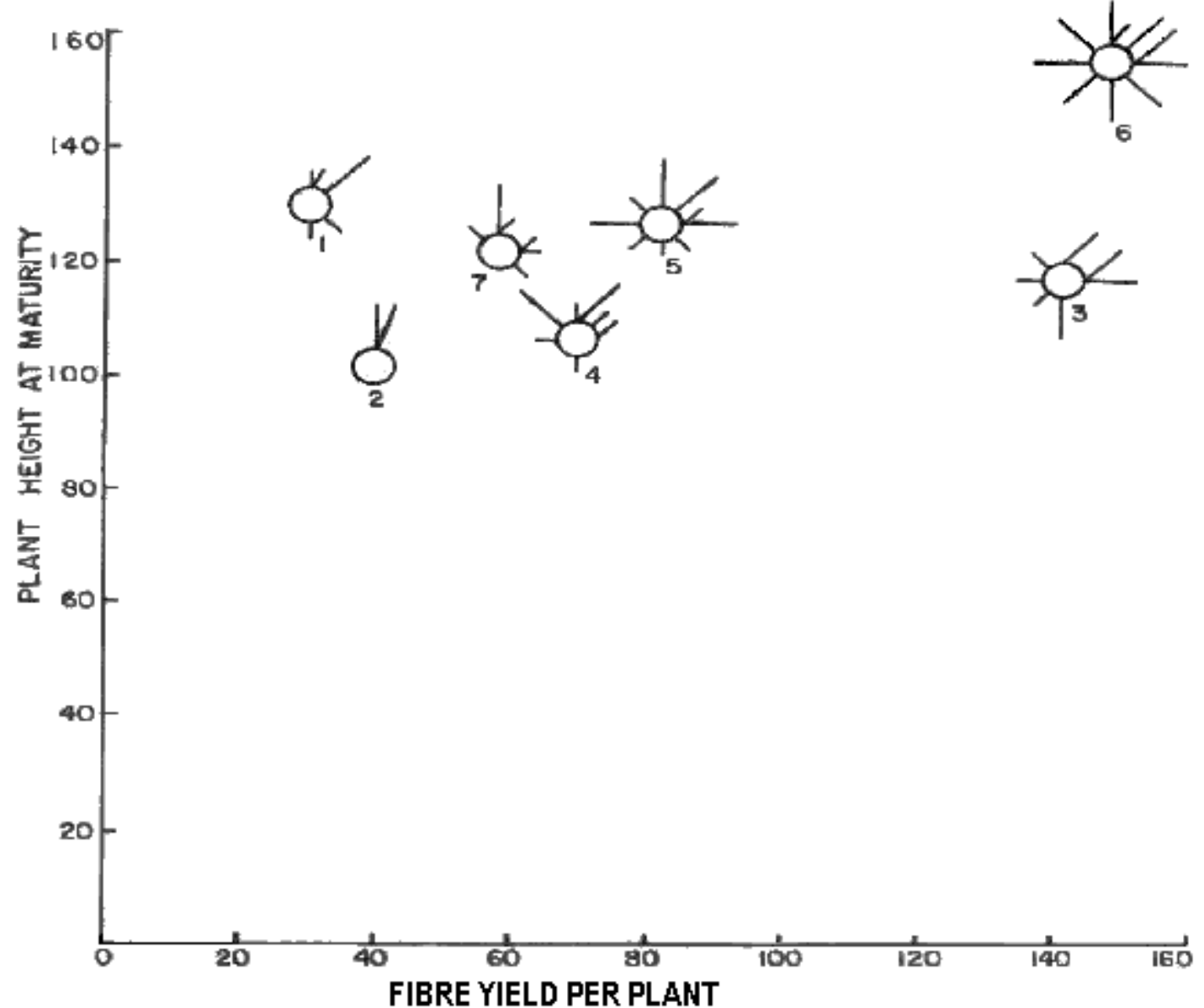

Fig. 1. Metroglyph diagram of different characters in 7 cultivars of cotton. The cultivar numbers are the same as in Table I

(NLFF) and plant spreading at first flowering (PSFF) and cultivar no. 7 for only days to first flowering (DFF). For the remaining characters the three cultivars showed medium and low values.

The exceptional and striking feature in this study is the off location of cultivars BAC-49 (no. 3) and JA/ 96-B (no. 6). Cultivar no. 3 showed high values for plant height at first flowering (PHFF), number of branches at first flowering (NBFF), number of seed per ball (NSB) and fibre yield per plant (FYP). In addition to plant height at maturity (PHM) and fibre yield per plant (FYP), cultivar no.6 also showed highest values for all other characters except number of seed per ball (NSB).

The pattern of morphological variations were first studied by Anderson (1957) from the results of metroglyph. Ramanujan and Kumar (1964), Mukherjee et al. (1971), 
Venkata Rao et al. (1973), Singh and Choudhury (1974), Mehra and Peter (1980), Kabir et al. (1993) and Khan and Kabir (1996) has also used this technique in different varieties of maize, tabacco, green gram, cicer, chilli and other crop species. In the present study the two most variable characters were plant height at maturity (PHM) and fibre yield per plant (FYP). Mehra and Peter (1980) identified fruit per plant and yield per plant as two most variable characters in metroglyph study of chilli.

\section{Conclusion}

In the present investigation, seven cultivars of cotton were studied for morphological variations following the method of metroglyph analysis. It is found from the metroglyph diagram that two clusters were found. Cluster I comprised of two cultivars viz., DPL-41 and DPL-20. Cluster II consists of three cultivars viz., DPL-50, DPL-51 and DPL-90. Cultivars of cluster I are closely associated with each other. In the same way cultivars of cluster II are also closely associated with each other. It indicates that they are genetically close to each other. Considering this fact selection of cultivars can be made from the same cluster for taking efficient breeding program for the improvement of this crop.

\section{References}

Anderson, E. (1957) A semigraphical method for the analysis of complex problems. Proc.
Nat. Acad. Sci. Wash,. 43: 923-927.

Kabir, G.; Singh, R.M. and Ramakrishna, K. (1993) Metroglyph analysis in six species of cicer. Bangladesh J. Bot. 22(1): 41-47.

Khan, M.R. and Kabir, G. (1996) Metroglyph analysis in Capsicum annuum $L$. Bangladesh J. Bot. 25(2): 171-176.

Mehra, C.S. and Peter., KV. (1980) Genetic divergence in chilli. Indian J. Agric. Sci. 50(6): 477- 481 .

Mukherjee, M.K. Gupta, N.B. Singh, S.B. and Singh, N. N. (1971) Metroglyph analysis of Indian and exotic varieties of maize. Euphytica 20: 113-118.

Ramanujan, S. and Kumar, S. (1964) Metroglyph analysis of geomorphological complexes in Indian varieties. Indian J. Genet. 24 : 144 150.

Singh, V.P. and Choudhury, R.K. (1974) Metroglyph and index score analysis of morphological variation in green gram (Phaseolus aurens L.) HAUJ Res. 4: 296 299.

Venkata Rao, C. Krishnamurty, K.V. and Lakshminarayana, R. (1973) Metroglyph analysis of morphlogical variation in fluencured tobacco (Nicotiana tobacum L.). Indian J. Agric. Sci. 43: 170 - 172.

Received : September, 04, 2006;

Accepted : 2007 